\title{
Increased Wind Erosion from Forest Wildfire: Implications for Contaminant-Related Risks
}

\author{
Jeffrey J. Whicker,* John E. Pinder III, and David D. Breshears
}

\begin{abstract}
Assessments of contaminant-related human and ecological risk require estimation of transport rates, but few data exist on wind-driven transport rates in nonagricultural systems, particularly in response to ecosystem disturbances such as forest wildfire and also relative to water-driven transport. The Cerro Grande wildfire in May of 2000 burned across ponderosa pine (Pinus ponderosa Douglas ex P.\&C. Lawson var. scopulorum Englem.) forest within Los Alamos National Laboratory in northern New Mexico, where contaminant transport and associated post-fire inhalation risks are of concern. In response, the objectives of this study were to measure and compare wind-driven horizontal and vertical dust fluxes, metrics of transport related to wind erosion, for 3 yr for sites differentially affected by the Cerro Grande wildfire: unburned, moderately burned (fire mostly confined to ground vegetation), and severely burned (crown fire). Wind-driven dust flux was significantly greater in both types of burned areas relative to unburned areas, by more than one order of magnitude initially and by two to three times $1 \mathrm{yr}$ after the fire. Unexpectedly, the elevated dust fluxes did not decrease during the second and third years in burned areas, apparently because ongoing drought delayed post-fire recovery. Our estimates enable assessment of amplification in contaminantrelated risks following a major type of disturbance - wildfire, which is expected to increase in intensity and frequency due to climate change. More generally, our results highlight the importance of considering wind- as well as water-driven transport and erosion, particularly following disturbance, for ecosystem biogeochemistry in general and human and ecological risk assessment in particular.
\end{abstract}

$\mathrm{P}$ ROCESSES driving erosion and transport of soil and associated nutrients and contaminants are of central concern for a diverse set of issues related to ecosystem management and risk assessment. Soil loss and redistribution through erosion can result in significant shortand long-term effects on human and ecosystem health (Whicker and Schultz, 1982; Saxton, 1995; Schlesinger and Pilmanis, 1998; Griffin et al., 2001; Toy et al., 2002; Whitford, 2002; Kaiser, 2004). Accelerated soil loss is considered to be one of the most pressing environmental problems, particularly in parts of Africa, South Asia, and Latin America (Toy et al., 2002; Kaiser, 2004), prompting some to refer to soil as an endangered ecosystem (Pimentel, 2000). Increased rates of soil erosion are

J.J. Whicker, Los Alamos National Laboratory, Health Physics Measurements Group, Mail Stop J573, Los Alamos, NM 87545. J.E. Pinder III, Colorado State University, Department of Environmental and Radiological Health Sciences, 1618 Campus Delivery, Ft. Collins, CO 80523. D.D. Breshears, University of Arizona, School of Natural Resources and Institute for the Study of Planet Earth and Department of Ecology and Evolutionary Biology, Biological Sciences East 325, P.O. Box 210043, Tucson, AZ 85721-0043. Received 31 Mar. 2005. *Corresponding author (jjwhicker@lanl.gov).

Published in J. Environ. Qual. 35:468-478 (2006).

Technical Reports: Landscape and Watershed Processes

doi:10.2134/jeq2005.0112

(c) ASA, CSSA, SSSA

677 S. Segoe Rd., Madison, WI 53711 USA largely the direct and indirect results of anthropogenic land use practices, especially those that cause intense, large-scale disturbances to vegetation communities (McNeill and Winiwarter, 2004). Accelerated soil erosion can be associated with high rates of nutrient loss from and redistribution within ecosystems and watersheds that lower soil quality (Baker and Jemison, 1991; Tongway and Ludwig, 1997; Schlesinger and Pilmanis, 1998; Whitford et al., 1998; Aguiar and Sala, 1999; Okin et al., 2001; Ludwig et al., 2002; Toy et al., 2002; Selmants et al., 2003; Miller, 2004; Wardle et al., 2004).

Soil erosion is driven by both water and wind, but most studies of soil erosion in nonagricultural settings have focused on water-driven rather than wind-driven processes. However, recent data estimating the relative rates of water- and wind-driven erosion and transport suggest that wind-driven processes have similar, and in many cases greater, impact on loss and local redistribution of soil in semiarid grassland, shrubland, and forest ecosystems (Breshears et al., 2003). Wind erosion is also important at regional and global scales, where dust storms impact human and environmental health and could provide important feedbacks to climate variability and change (Tegen et al., 1996; Griffin et al., 2001).

Wind erosion can also be important in determining risk levels associated with contaminant transport due to potential inhalation of airborne contaminated soils (Whicker and Schultz, 1982; Larney et al., 1999). Inhalation of radioactive aerosols from the wind-driven transport of soils contaminated with low levels of radionuclides, such as ${ }^{137} \mathrm{Cs}$ and ${ }^{239} \mathrm{Pu}$, has been the focus of risk assessments at many Department of Energy and Department of Defense facilities across the USA (Anspaugh et al., 1975; National Academy of Science, 1989). These risk assessments are generally made under assumptions of undisturbed environments and often do not consider the potential for increased mobility of soilbound contaminants following severe environmental disturbances, though these are of public and scientific concern (Whicker et al., 2004a).

Soil erosion can increase greatly following environmental disturbances that lower vegetation cover and disturb surface soils due to the nonlinear relationship between ground cover and erosion rate for both wind and water erosion (Fryrear, 1985; Johansen et al., 2001). There are limited studies, however, quantifying changes in erosion rates following environmental disturbance, particularly for wind erosion (Zobeck et al., 1989; Whicker et al., 2002). Yet those studies suggest that

\footnotetext{
Abbreviations: ANOVA, analysis of variance; Big Spring Number Eight (BSNE) samplers; HDF, horizontal dust flux; LCM, linear contrast of means; LANL, Los Alamos National Laboratory; VDF, vertical dust flux.
} 
wind erosion rates can increase by more than an order of magnitude following disturbance. Disturbances in semiarid ecosystems are common and result from phenomena such as drought, insect breakouts, disease, fire, or through anthropogenic activities such as tree harvesting (Freedman, 1995; Rodgers, 1996). Among the many types of disturbance that can reduce ground cover, wildfire stands out as perhaps having the greatest potential for rapidly reducing ground cover and thereby increasing erosion rates (Johansen et al., 2001; Nyhan et al., 2001; Whicker et al., 2002). While there are numerous studies on the response of water erosion to wildfire (Nyhan et al., 2001; Johansen et al., 2001), there are few data on wind erosion rates in semiarid forests (Breshears et al., 2003) and even fewer data evaluating post-fire changes in wind-driven erosion and transport in this important ecosystem. In the case of wildfire, post-fire climate or treatments such as seeding and mulch cover should alter the rates of recovery in ground cover (Veenis, 2000), but studies evaluating such post-fire recovery effects on wind erosion are lacking.

The effects of wildfire on soil erosion are of increasing concern in the ponderosa pine forests of the semiarid west because a combination of overgrazing and fire suppression has led to overgrown tree stands with high fuel loads that are vulnerable to catastrophic wildfires (Friederici, 2003). The forests are particularly susceptible during periods of drought (Swetnam and Betancourt, 1998), which can occur over extended intervals (McCabe et al., 2004). In summary, there are few data that allow assessment of how wind erosion might increase in fire-vulnerable, semiarid forests following wildfire, or on how persistent possible post-fire increases in wind erosion might be.

The objective of this study was to compare the relative rates of wind-driven dust flux in burned and unburned ponderosa pine forest, as related to characteristics of local vegetation, soil, micrometeorology, and burn severity. Specifically, we (i) compared horizontal dust flux across a gradient of burn severities as a function of sampling height, (ii) showed that horizontal dust flux measures are correlates of direct wind erosion as measured by vertical dust flux, and (iii) analyzed temporal trends in horizontal dust flux for a period from 1 to $3 \mathrm{yr}$ following the fire and related the trends to the recovery of forest floor vegetation and litter cover.

\section{MATERIALS AND METHODS}

\section{Study Sites}

Our study was conducted on the Pajarito Plateau located in the Jemez Mountains of northern New Mexico, USA, near Los Alamos. In May of 2000, the Cerro Grande fire burned more than 19000 ha of mostly dense ponderosa pine forest in the Jemez Mountains. This fire also burned approximately 3000 ha of the LANL (Los Alamos National Laboratory; Los Alamos National Lab., 2000). Numerous locations on LANL property with the potential to be contaminated with either radioactive (e.g., depleted $\mathrm{U}$ and $\mathrm{Pu}$ ) or chemical materials (Fresquez et al., 1998; Veenis, 2000) were burned (Kraig et al., 2001), and because the fire dramatically removed live tree density and ground cover (vegetation and litter), it exposed these sites to water and wind erosion (Fryrear, 1985; Johansen et al., 2001;
Pinder et al., 2004). Wind transport in burned areas could be an especially important mechanism for redistribution, concentration, and off-site transport of these contaminated soils (Anspaugh et al., 1975; Whicker and Schultz, 1982; Gonzales et al., 2001; Breshears et al., 2003). While the initial levels of public intakes of these contaminants during the Cerro Grande fire has been evaluated and considered to have presented little health risk (Los Alamos National Lab., 2000; Kraig et al., 2001), there is still concern about the long-term, post-fire effects on continued dust emissions from LANL (Los Alamos National Lab., 2002).

The study was conducted at six sites along the western edge of LANL $\left(35^{\circ} 52^{\prime} \mathrm{N}\right.$ lat; $106^{\circ} 21^{\prime} \mathrm{W}$ long) at an elevation of about $2400 \mathrm{~m}$ (Fig. 1). Measurements of wind-driven dust were made from May 2001 through July 2003. The sites are on relatively flat mesa tops with slopes $<10 \%$ (Breshears et al., 2003). Vegetation was dominated by ponderosa pine before the fire. To ensure that locally eroding material was captured, the sampling sites were centrally located within a relatively homogeneous area of vegetation with at least $100 \mathrm{~m}$ downwind distance along the dominant wind directions (from the west, southwest, or northwest) from any road or new disturbance. The criteria for the 100-m distance was based on data from Baldocchi (1997) that suggested that most of the eroding soil in

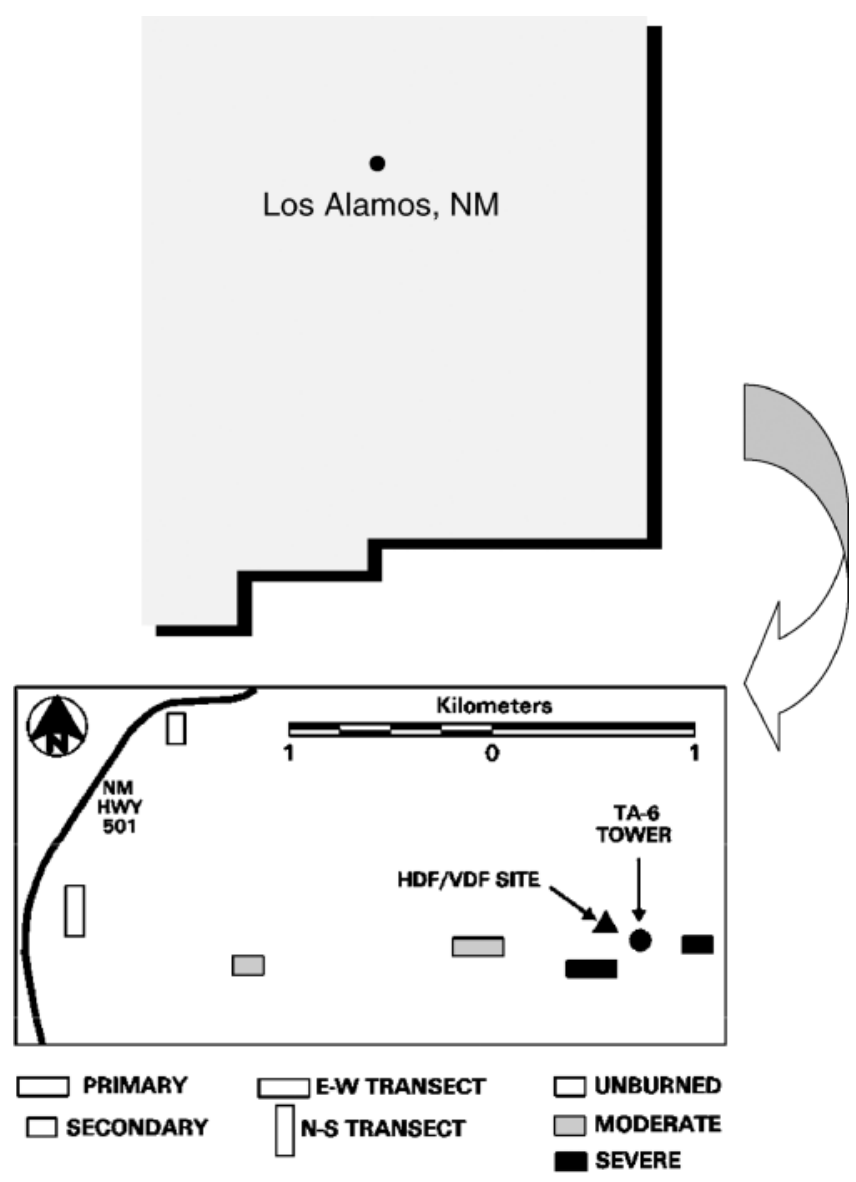

Fig. 1. Location of sampling plots relative to New Mexico, USA, and New Mexico State Highway 501, which borders the west side of Los Alamos National Laboratory. The burn gradient is represented as variously shaded boxes. Within each burn category, the primary sampling sites are represented as larger rectangles and secondary sites represented as smaller rectangles. The map also shows the locations of the TA-6 meteorological tower and the sites used to establish relationships between HDF (horizontal dust flux) and VDF (vertical dust flux). 
a thick forest is collected at a distance of $10 \mathrm{~m}$ (analog for unburned forest), and the distance should be $<100 \mathrm{~m}$ for vegetated but treeless areas, which is an analog for the severely burned area (Stout, 1990; Zobeck et al., 2003). Therefore, the selected distance of $100 \mathrm{~m}$ was considered to be conservative for all sampling sites. A line transect was established in the center of each sampling site along which two or three dust sampling stations were positioned every $30 \mathrm{~m}$.

For the purposes of this study, the range of forest fire damage was classified into three broad categories including unburned, moderately burned, and severely burned (Pinder et al., 2004). Unburned sites were those where there was no evidence of fire damage. Moderately burned sites were those where the fire had consumed the ground vegetation and litter and had scorched but not consumed the pine needles. Some tree mortality occurred at moderate sites. At severely burned sites, the fire had consumed the ground vegetation and litter and had extended up into the canopy, consuming all the needles and killing the vast majority of the trees. Remediation practices of seeding with annual and biennial forbs and mulching with straw were applied to these severely burned sites within a few months following the fire (Veenis, 2000). Within each burn category, two sites were selected to assess variability within burn categories. Because of equipment limitations, one site was termed the primary site and had greater sampling intensities than the other site, which was termed the secondary site.

\section{Site Characterization}

To document the magnitude of fire effects and measure the rate of system recovery for important variables impacting dust flux, measurements of vegetation cover, litter cover, tree canopy cover, and soil texture were made at each site (Pinder et al., 2004). Fire effects on individual trees were measured as mortality and canopy scorching (i.e., the percentage of the tree's canopy with scorched needles). Fire recovery was measured as the development of litter and vegetation cover on the soil. Micrometeorological measurements were made in the primary severely burned and unburned plots, and also at the TA-6 (Technical Area-6) meteorological station operated by LANL, which was within $3 \mathrm{~km}$ of all sampling areas.

\section{Fire Effects on Forest Structure}

Tree structure in burned and unburned sections of forest was characterized by measuring tree density and tree heights in $100-\mathrm{m}^{2}$ plots. There were five randomly selected plots within each primary site, and four plots within each secondary site. Tree heights were measured using a forester's altimeter. The percentage of live tree canopy cover was measured in June 2001 using a concave mirror spherical densiometer that reflects a vertical view of the tree canopy (Lemmon, 1956). The spherical densiometer measurements were made at 15 and 12 locations in primary and secondary sampling sites, respectively.

Recovery of ground vegetation and litter cover was assessed using digital photographs of $1-\mathrm{m}^{2}$ plots taken at early spring, midsummer, and late summer for the length of the project (June 2001-August 2003; Pinder et al., 2004). These pictures were taken from a height of approximately $2 \mathrm{~m}$ and at an angle from the vertical of about $25^{\circ}$. The 3.2 megapixel images were magnified $(\geq 2 \times)$, and the cover percentage for each of the vegetation-cover plots determined by visual estimation of the percentage of cover of live vegetation and litter within 25 subplots. Vegetation and litter cover were separately evaluated within each subplot. A separate measure of the total cover was estimated from 81 points dispersed throughout the $1-\mathrm{m}^{2}$ plot (Pinder et al., 2004).

\section{Soil Sampling}

Separate soil samples were collected in July 2003 from five random locations within each primary site and three random locations in each secondary site. Twenty 20-mm-deep and 38 -mm-diameter cores were collected around a $1-\mathrm{m}^{2}$ frame at each soil sampling location and composited. Litter cover was carefully scraped aside to collect only the upper horizon of soil. The soil was then air dried and submitted to the Colorado State University's Soil, Water, and Plant Testing Laboratory for measures of sand, silt, and clay percentage by mass.

\section{Meteorological Conditions}

Meteorological data collection stations (Davis Instruments Corp., Hayward, CA), which measured wind velocities at $1 \mathrm{~m}$, precipitation, and temperature in 15 -min averages, were installed at the primary severely burned and the primary unburned sites. Additional meteorological data were taken from a LANL-operated 46-m-tall meteorological tower located within $3 \mathrm{~km}$ of all the sampling sites. The LANL TA-6 meteorological station provided 15 -min-averaged data on a number of meteorological conditions such as precipitation amounts and wind velocities at 11.5, 23, 46, and $92 \mathrm{~m}$ (Rishel et al., 2003).

\section{Horizontal Dust Flux Measurements}

Horizontal dust flux (HDF) is a measure of material transport associated with wind erosion (Breshears et al., 2003) and was measured using BSNE (Big Spring Number Eight) samplers (Fryrear, 1986). A tail fin attached to each BSNE sampler orients their $10-\mathrm{cm}^{2}$ opening into the wind where airborne dust enters and is deposited onto a collection pan as winds decelerate through wider portions of the sampler. The BSNE field dust collectors have been extensively tested and have good sampling efficiency for soils with high fractions of sand and silt (Fryrear, 1986; Goossens and Offer, 2000) such as those that are abundant at LANL (Nyhan et al., 1978). The HDF was calculated by using the mass of the dust collected (dried at $50^{\circ} \mathrm{C}$ to a constant mass) divided by the area of the sampler opening $\left(10 \mathrm{~cm}^{2}\right)$ and the length of the sampling period. The units of HDF were then expressed as grams per square meter per day. This value represents a measure of the wind-driven mass of dust flowing horizontally along the earth surface at a particular height as measured by a single sampler. It should be noted that some other researchers have limited the term dust to describe the fine soil fraction but not the larger sand and silt fraction (Goossens and Riksen, 2004). However, others have used "dust" in a more generic sense to mean a suspension of nonspecific solid particles in air that have been formed by the mechanical disintegration of a parent material and whose size generally ranges from 1 to $10000 \mu \mathrm{m}$ (Hinds, 1982; Pye, 1987), although the particles collected in this study were suspended a significant period of time and have diameters generally $<500 \mu \mathrm{m}$ (Hinds, 1982; Pye, 1987; Stout and Zobeck, 1996). Therefore, we use the term dust in a more generic sense, without reference to particle size or composition (e.g., mineral or organic).

Multiple BSNE samplers may be mounted at different heights to measure gradients in HDF with increasing distance above the soil surface. Lack of highly time-resolved measurements of particle size and wind velocity in the sampling areas precluded corrections for collection efficiency, so a collection efficiency of $100 \%$ was assumed and will bias the measured HDF estimates low.

Three dust sampling stations were used in the primary sampling sites and two were used in the secondary sampling sites. A typical BSNE sampling station consisted of three BSNE 
samplers at heights of $0.25,0.5$, and $1 \mathrm{~m}$. Additionally, recognizing that others have found sharp gradients of mass flux with sampling height (Zobeck et al., 2003), a limited number of BSNE measurements were made at heights of 0.07 and $0.18 \mathrm{~m}$ during the second and third year of the study. This allowed better assessment of HDF profiles with sampling height because most wind-driven dust mass occurs near soil surfaces, with about $99 \%$ occurring below a height of $1 \mathrm{~m}$ (Stout and Zobeck, 1996). A nonlinear least-squares method was used to determine the parameters for an exponential relationship between height and the height-specific average HDF. This exponential relationship was then integrated to determine the total horizontal mass passing through a 1-m-wide length of ground surface (Stout and Zobeck, 1996; Gillette et al., 1997). These self-orienting samplers also integrate horizontal flux for all wind directions, so the integrated horizontal flux represents the horizontal flux passing through a rotating 1-m-wide gate up to a height of $1 \mathrm{~m}$ (Breshears et al., 2003).

Measurements of HDF were collected beginning in May 2001 and extended through July 2003. Samples were collected generally at weekly to biweekly intervals in 2001 from June through November, in 2002 from January through November, and from March through July in 2003. Many of these collections were obtained from the same or overlapping intervals in different years. Constraints of resources imposed the midyear to midyear sampling program, and the complicating effects that seasonal weather patterns of precipitation and wind speeds would have on HDF data were not immediately appreciated. The effects of these seasonal influences on HDF and the complications imposed on comparing data among years will be discussed below.

Relationships between the HDF and meteorological conditions were established using 1-m wind and precipitation data from the meteorological station and HDF measurements from three nearby BSNE sampling stations. These HDF measurements were made from May 2001 to September 2002 in an open, unforested area.

\section{Vertical Dust Flux Measurements}

Contrary to HDF, vertical dust flux (VDF) measurements made at heights $>1 \mathrm{~m}$ indicate dust that is available for longdistance transport and generally consists of smaller, respirable particles that are important for health risk assessments (Stout and Zobeck, 1996; Breshears et al., 2003). Therefore, VDF was measured at the TA- 6 meteorological tower, which is located in the middle of an $\sim 200$-m opening in the forest that contains mostly low-lying ( $\sim 0.5 \mathrm{~m}$ in height) vegetation (Fig. 1$)$. The VDF was calculated as the product of the eddy diffusivity coefficient $\left(K_{\mathrm{z}}\right)$ and the concentration gradient in the vertical direction (Blackadar, 1997), with $K_{\mathrm{z}}$ being equal to the product of the von Karmon constant (0.4), the sampling height of the wind velocity measurements, and the friction velocity $\left(u_{*}\right)$.
Friction velocities were measured at a height of $11.5 \mathrm{~m}$ by a sonic anemometer at the TA-6 tower (Rishel et al., 2003) and the dust mass concentrations were measured by drawing air through glass-fiber filters placed at 1- and 3-m sampling heights as described in Whicker et al. (2002). Friction velocity was measured between August 2000 and August 2001, and a subset of friction velocity measurements obtained at night, when neutral atmospheric stability was more likely, was used in these calculations.

The VDF measurements were statistically correlated to HDF measurements made from the BSNE samplers also located near the TA-6 meteorological tower using data from overlapping time periods. The VDF-HDF sites, the Davis meteorological station, and TA-6 meteorological station were arranged in a triangular pattern with approximately $200 \mathrm{~m}$ per side (Fig. 1).

\section{Statistical Analyses}

Statistical comparisons of HDF among burned and unburned areas were performed using a mixed-model ANOVA (analysis of variance) where burn severity, sampling periods, and the interaction of burn severity and sampling dates were fixed effects, and sites and specific BSNE locations within sites were random effects (Milliken and Johnson, 1984). Statistical computations were performed using the Type 3 option of PROC MIXED of the SAS System (Littell et al., 1996). Hypotheses of specific effects, such as (i) the effects of specific burn severities and (ii) changes in the effects of burn severities among years, were tested using $F$ ratios computed for LCMs (linear contrasts of means; Littell et al., 1996). Due to the differential effects of precipitation and wind speeds on HDF at different elevations, separate analyses were performed for the 0.25-, 0.5-, and 1.0-m elevations, and separately for all and for dry sampling periods. The relationship between the HDF measurements made during dry sampling periods and sampling height was determined using a simple exponential function and integrated to obtain estimates of total horizontal flux through a 1-m-wide vertical plane. This analysis also allowed relative comparisons with other wind and water erosion measurements reported in similar studies.

\section{RESULTS}

\section{Impact of Fire on Tree and Ground Cover}

Measurements made in 2001 (details in Pinder et al., 2004) show large decreases in tree canopy cover along the burn severity gradient, with almost no live tree cover in the severely burned area, and tree cover in the moderately burned about $50 \%$ of that found in the unburned location (Table 1). Our sampling locations also captured some of the heterogeneity of tree density and tree cover

Table 1. Site characterization data for the burned and unburned plots. Values provided are means \pm 1 standard deviation.

\begin{tabular}{|c|c|c|c|c|c|c|c|c|c|}
\hline \multirow[b]{2}{*}{ Site } & \multicolumn{4}{|c|}{ Tree cover } & \multicolumn{2}{|c|}{ Ground cover } & \multicolumn{3}{|c|}{ Soil characteristics } \\
\hline & Trees ha $\mathbf{h a}^{-1}$ & Total cover & Live canopy & Avg. tree height & Vegetative cover & Litter cover & Sand & Silt & Clay \\
\hline & & 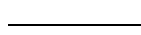 & 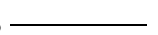 & $\mathbf{m}$ & 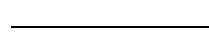 &  & 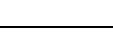 & 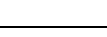 & 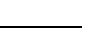 \\
\hline \multicolumn{10}{|l|}{ Unburned } \\
\hline Primary & $1280 \pm 450$ & $97 \pm 4$ & $\mathbf{7 8} \pm \mathbf{1 4}$ & $9.4 \pm 4.6$ & $5 \pm 6$ & $98 \pm 4$ & $39 \pm 9$ & $49 \pm 5$ & $12 \pm 4$ \\
\hline \multirow{2}{*}{\multicolumn{10}{|c|}{ Moderate burn }} \\
\hline & & & & & & & & & \\
\hline Primary & $560 \pm 440$ & $78 \pm 16$ & $38 \pm \mathbf{3 0}$ & $9.6 \pm 4.1$ & $5 \pm 7$ & $79 \pm 19$ & $46 \pm 7$ & $45 \pm 7$ & $\mathbf{9} \pm \mathbf{1}$ \\
\hline Secondary & $1180 \pm \mathbf{3 5 0}$ & $83 \pm 16$ & $35 \pm 18$ & $9.4 \pm 4.0$ & $13 \pm 12$ & $83 \pm 20$ & $36 \pm 3$ & $52 \pm 2$ & $13 \pm 2$ \\
\hline \multicolumn{10}{|l|}{ Severe burn } \\
\hline Primary & $240 \pm 190$ & $51 \pm \mathbf{1 1}$ & $\mathbf{0} \pm \mathbf{0}$ & $11.8 \pm 4.8$ & $24 \pm 16$ & $38 \pm \mathbf{1 8}$ & $34 \pm 2$ & $54 \pm 2$ & $12 \pm 1$ \\
\hline Secondary & $800 \pm 670$ & $52 \pm 16$ & $1 \pm 2$ & $13.8 \pm 2.7$ & $26 \pm 17$ & $39 \pm 18$ & $51 \pm 5$ & $39 \pm 7$ & $9 \pm 3$ \\
\hline
\end{tabular}




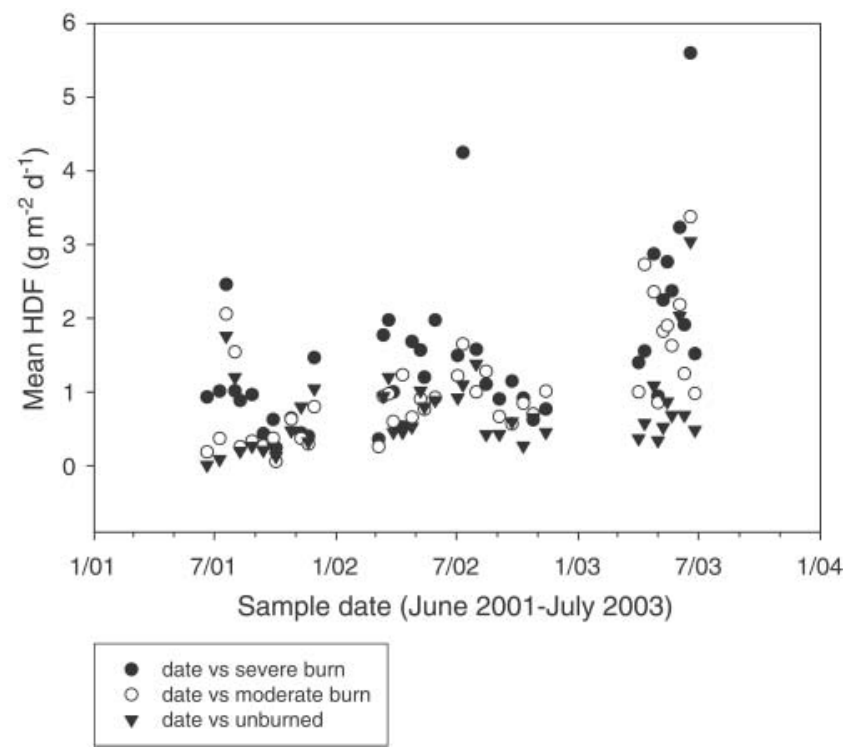

Fig. 2. Mean HDF (horizontal dust flux) at 1-m sampling heights categorized by burn type.

typically found in ponderosa pine forests, as we found significant differences in tree cover within burned and unburned types.

Statistical comparisons for vegetation cover showed significantly more vegetation cover in the severely burned areas than the moderately burned and unburned areas, which was due to both viable biological residual and the extensive remediation efforts in the severely burned areas. While the remediation effort probably increased the initial surge in vegetation cover following the fire, we found that the vegetation cover in the severely burned sites decreased each year from 2001 to 2003, which is probably the result of ongoing drought persisting throughout the study period (Pinder et al., 2004).

Statistical comparisons for litter cover showed that there was significantly greater litter cover in the unburned sites (mostly dead pine needles) than that found in either the moderately or severely burned sites. Litter cover in both the moderately and severely burned sites increased from 2001 to 2002, with no further increase from 2002 to 2003 (Pinder et al., 2004). Litter cover on moderately burned sites was composed of recently shed, scorched pine needles over bare earth that was exposed by the fire.

Trends in total cover (vegetation plus litter) showed greatest total cover in the unburned sites, next was the moderately burned sites, and finally, the lowest total cover was found in the severely burned sites (Table 1). Total cover increased from 2001 to 2002 in both the severely and moderately burned locations mostly from additional litter accumulation. There was no change in total cover with time in the unburned location (Pinder et al., 2004).

Soils are dominated by sand and silt; textural classes represented are loams, silt loams, and a sandy loam (Table 1). A statistical comparison of soil texture showed no significant differences in soil composition between the different burn locations and there was more variation within burn types than among burn types (Pinder et al., 2004).

\section{Impact of Fire on Horizontal Dust Flux}

The HDF varied across time and among burn categories (Fig. 2), with a generally increasing trend in HDF with burn severity (Table 2). The magnitude of the differences in HDF among burned sites declined with sampling height (Fig. 3a).

The ANOVA showed that the HDF measured on severe burn areas were significantly (all LCM $F$ values $>4.5$; $\mathrm{df}=1,>465 ; P<0.05)$ greater than those on unburned areas in all years and at all sampling heights. The profile of HDF with elevation showed greater increases at the $0.25-\mathrm{m}$ height than at the $1.0-\mathrm{m}$ height for all $3 \mathrm{yr}$. For example, mean ( \pm standard error of mean) increases in HDF in 2003 were $7.79 \pm 0.74,2.52 \pm 0.19$, and $2.04 \pm$ 0.19 at $0.25-, 0.50-$, and $1.0-\mathrm{m}$ heights, respectively.

The response of HDF to the moderate burn was less distinct than that for the severe burn, but the mean HDF on the moderate burns was always greater than that on the unburned areas. Mixed-model ANOVA and LCM analyses based on these data did not indicate any significant difference between moderate and unburned areas; however, these comparisons were compromised by skewness in the data (Table 2), as indicated by standard

Table 2. The HDF (horizontal dust flux) on burned and unburned areas in 2001, 2002, and 2003. Data are shown as means \pm 1 standard deviation and are computed for data from both primary and secondary sites from all sampling periods. Data in parentheses are derived from dry sampling periods ( $<1.3 \mathrm{~mm}$ precipitation).

\begin{tabular}{|c|c|c|c|c|c|c|}
\hline Sampling height & $n$ & HDF at unburned site & $n$ & HDF at moderate burned site & $n$ & HDF at severely burned site \\
\hline $\mathbf{m}$ & & $\mathrm{g} \mathrm{m}^{-2} \mathrm{~d}^{-1}$ & & $\mathbf{g ~ m}^{-2} \mathbf{d}^{-1}$ & & $\mathbf{g ~ m}^{-2} \mathbf{d}^{-1}$ \\
\hline \multicolumn{7}{|c|}{2001} \\
\hline 0.25 & $60(15)$ & $0.45 \pm 0.48(0.25 \pm 0.18)$ & 59 (14) & $0.95 \pm 1.26(0.47 \pm 0.49)$ & $60(15)$ & $5.53 \pm 8.18(0.76 \pm 0.33)$ \\
\hline 0.5 & 59 (15) & $0.45 \pm 0.48(0.28 \pm 0.23)$ & 60 (15) & $0.49 \pm 0.64(0.31 \pm 0.27)$ & $60(15)$ & $1.23 \pm 0.41(0.5 \pm 0.4)$ \\
\hline 1.0 & 59 (15) & $0.42 \pm 0.44(0.72 \pm 0.43)$ & 59 (14) & $0.46 \pm 0.55(0.33 \pm 0.32)$ & $60(15)$ & $0.76 \pm 0.41(0.43 \pm 0.22)$ \\
\hline \multicolumn{7}{|c|}{$\underline{2002}$} \\
\hline 0.25 & 79 (35) & $0.69 \pm 0.4(0.72 \pm 0.43)$ & 79 (35) & $1.31 \pm 1.34(0.82 \pm 0.53)$ & 80 (35) & $4.47 \pm 5.43(1.58 \pm 0.66)$ \\
\hline 0.5 & $80(35)$ & $0.7 \pm 0.41(0.79 \pm 0.44)$ & $80(35)$ & $0.93 \pm 0.54(0.78 \pm 0.32)$ & $80(35)$ & $1.71 \pm 0.99(1.68 \pm 0.76)$ \\
\hline 1.0 & $80(35)$ & $0.7 \pm 0.43(0.83 \pm 0.49)$ & $80(35)$ & $0.93 \pm 0.56(0.83 \pm 0.25)$ & $80(35)$ & $1.43 \pm 1.67(1.60 \pm 0.58)$ \\
\hline \multicolumn{7}{|c|}{2003} \\
\hline 0.25 & $60(35)$ & $1.05 \pm 0.97(0.59 \pm 0.28)$ & $60(35)$ & $2.10 \pm 2.15(1.17 \pm 0.61)$ & $60(35)$ & $8.72 \pm 15.59(2.14 \pm 1.20)$ \\
\hline 0.5 & $59(35)$ & $1.09 \pm 0.96(0.57 \pm 0.24)$ & $60(35)$ & $1.96 \pm 1.35(1.44 \pm 0.74)$ & 59 (34) & $3.60 \pm 3.94(1.93 \pm 0.97)$ \\
\hline 1.0 & $60(35)$ & $1.09 \pm 0.94(0.59 \pm 0.26)$ & $57(35)$ & $2.15 \pm 1.33(1.65 \pm 0.92)$ & 58 (33) & $3.09 \pm 2.95(1.92 \pm 0.87)$ \\
\hline
\end{tabular}


(a)

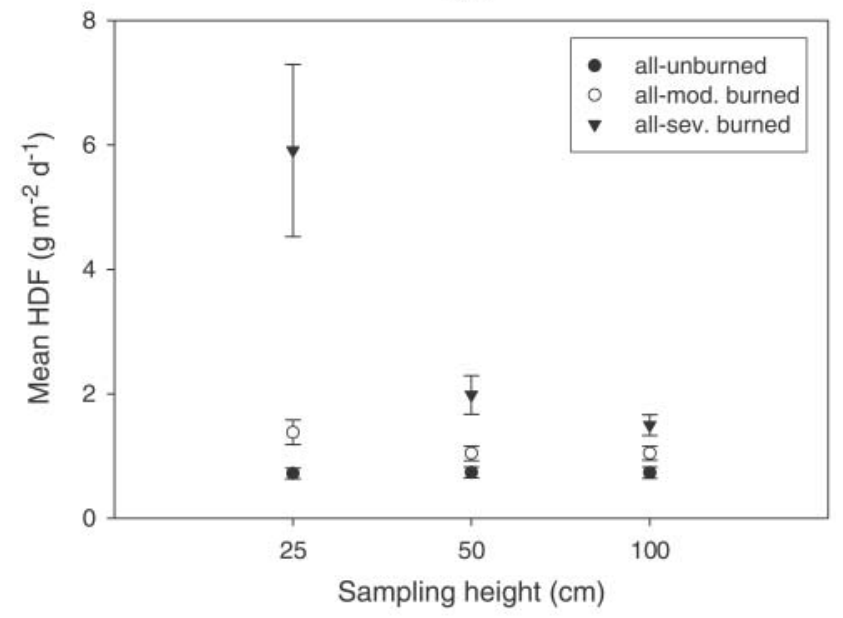

(b)

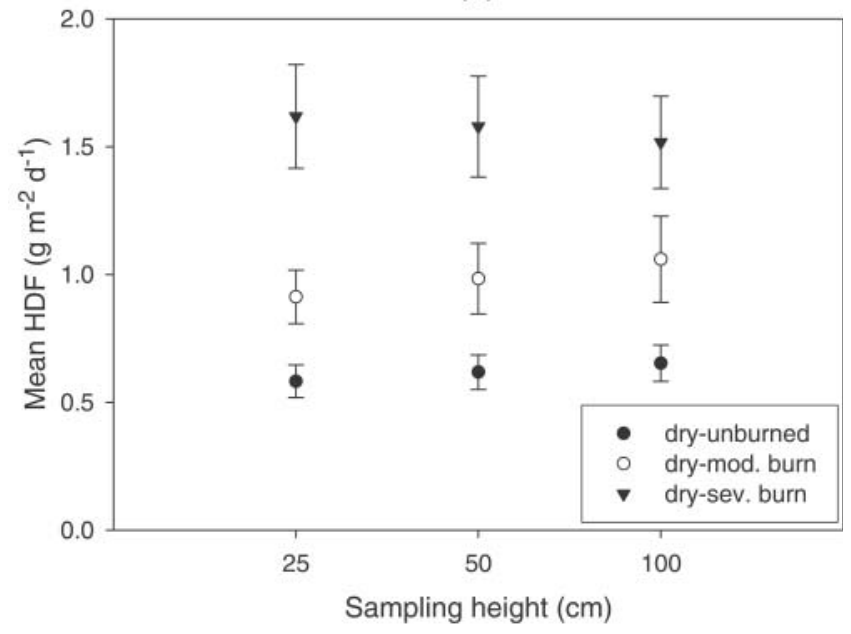

Fig. 3. Mean and 1 standard error for (a) HDF (horizontal dust flux) categorized by sampling heights and averaged across all sampling periods and (b) HDFs that were averaged across dry sampling periods with precipitation $<\mathbf{1 . 3} \mathbf{~ m m}$.

deviation to mean ratios being $>0.3$. The LCM analyses on logarithmic transformations of HDF, which moderate the effects of skewness, indicated significantly $(P<0.05)$ greater HDF on moderate burn sites at all time periods. The HDF measurements $<0$ were arbitrarily redefined as 0.03 before logarithmic transformations. Mean HDF on severe burn areas were significantly greater than those on moderate burn areas at all heights (all LCM $F$ values $>19 ; \mathrm{df}=1,4 ; P<0.05)$. The major difference between the response of HDF on severe and moderate areas was the greater increase on severe areas at the $0.25-\mathrm{m}$ elevation. For example, the mean ( \pm standard error) differences between severe and moderate burn areas in 2003 were $6.56 \pm 0.68,1.58 \pm 0.18$, and $0.94 \pm$ 0.19 at $0.25,0.50$, and $1.0 \mathrm{~m}$, respectively.

\section{Analysis of Fire Effects on Horizontal Dust Flux during Dry Periods}

Field observations of mud splash on the outside of the lowest BSNE samplers suggested the potential for additional collection of soil in the sampler from rain splash, thus prompting an analysis of HDF for both all sampling periods and periods with little or no rain (Table 2, Fig. 3a and $3 b$ ). The potential impact of precipitation and rain splash on HDF measurements was further investigated by correlating HDF measurements and total precipitation. The HDF measurements for this investigation were made adjacent to the TA-6 meteorological tower and the correlation showed that, as total precipitation in the sampling interval increased, there were corresponding increases in $\mathrm{HDF}$ at $0.25 \mathrm{~m}(F=17.3$; df $=1,46 ; P<$ $0.01)$ and $0.5 \mathrm{~m}(F=15.9 ; \mathrm{df}=1,45 ; P<0.01)$ as shown in Fig. 4, Column a. The increasing HDF with increasing precipitation probably results from rain splash during rain events. Although no direct measurements of rain splash were made, it is a plausible explanation based on (i) observations of mud splatter on sampler surfaces, (ii) rain splash being an effective mechanism for soil particle transport (Finkle, 1986), (iii) the possibilities that splashed particles could enter samplers through either the BSNE front opening or open top vent, and (iv) the fact that there was no statistically significant $(F=0.32$; $\mathrm{df}=1,46 ; P \geq 0.05$ ) increase in HDF at $1.0 \mathrm{~m}$ (a height that is generally greater than the height of rain splash; Finkle, 1986) with increasing precipitation. There was, however, a statistically significant $(F=6.1$; df $=1,46$; $P$ 0.05) increase in HDF at $1.0 \mathrm{~m}$ with increasing mean daily maximum wind speed (Fig. 4, Column b). Wind speeds had no statistically significant $(P>0.10)$ effects on HDF at 0.25 and $0.5 \mathrm{~m}$, possibly due to the overriding effects of rain splash.

To separate the effects of wind and rain splash, the HDFs were additionally compared among burned and unburned areas during dry periods. For this analysis, we selected sampling periods where precipitation during the sampling interval (generally $1-2 \mathrm{wk}$ ) was $<0.13 \mathrm{~cm}$. This precipitation threshold was considered to be low enough to have very little effect on the HDF (Fig. 4, Column a), yet provides enough sampling periods for robust statistical analysis. Although fewer sampling periods are available for statistical comparisons, the data indicate greater HDF on burned areas during dry periods than on unburned areas (Fig. 3b), consistent with the analysis using all data as shown in Fig. 3a. At $0.25 \mathrm{~m}$, the HDF measures across all $3 \mathrm{yr}$ were significantly greater on severe burn (LCM $F=368.2 ; \mathrm{df}=1,3 ; P \leq$ $0.01)$ and moderate burn areas (LCM $F=56.5 ; \mathrm{df}=1,3$; $P \leq 0.01)$. At $0.5 \mathrm{~m}$, the HDF was significantly greater on severe burn areas ( $\mathrm{LCM} F=24.8 ; \mathrm{df}=1,3 ; P \leq 0.05$ ) but not significantly greater on moderate burn areas $(P>0.10)$. At $1.0 \mathrm{~m}$, the $\mathrm{HDF}$ were statistically significantly greater on both severe areas (LCM $F=703.6$; $\mathrm{df}=1,3 ; P \leq 0.01)$ and moderate areas $(\mathrm{LCM} F=84.5$; $\mathrm{df}=1,3 ; P \leq 0.01)$.

The mean HDF for dry periods did not dramatically decrease between sampling heights of 25 to $100 \mathrm{~cm}$ as seen in the means from all sampling periods (Fig. 3b). We used the limited set of HDF measurements at heights of 7 and $18 \mathrm{~cm}$ in each of the burned and unburned primary sites to determine a best-fit exponential relationship between sampling height $(h)$ and mean HDF using data from the dry periods (to avoid potential 
(a)

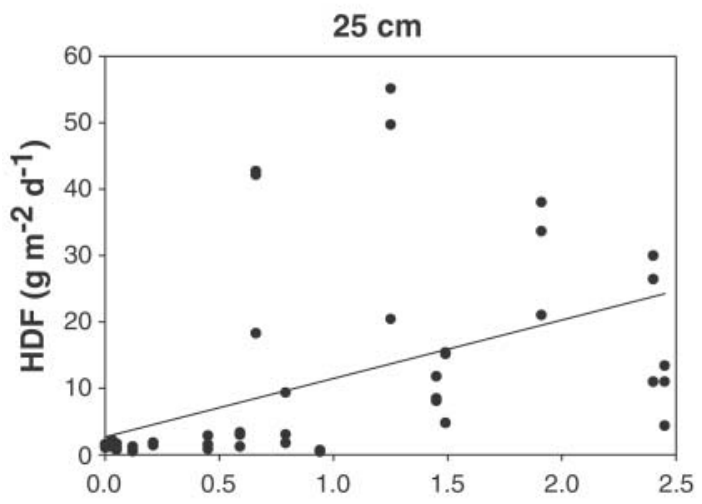

$50 \mathrm{~cm}$

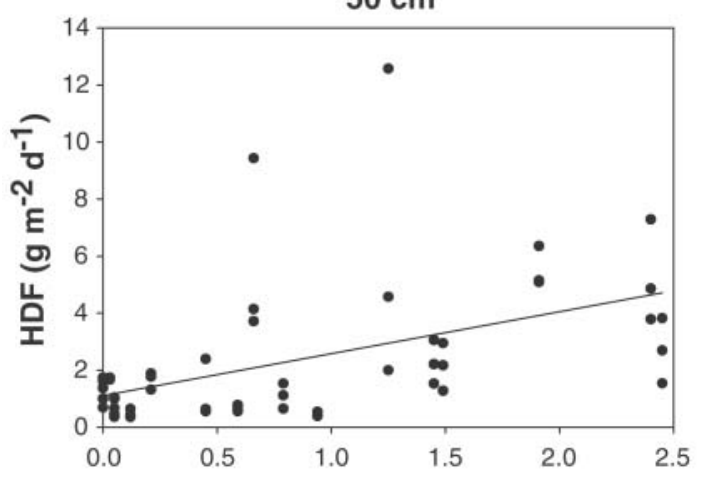

$100 \mathrm{~cm}$

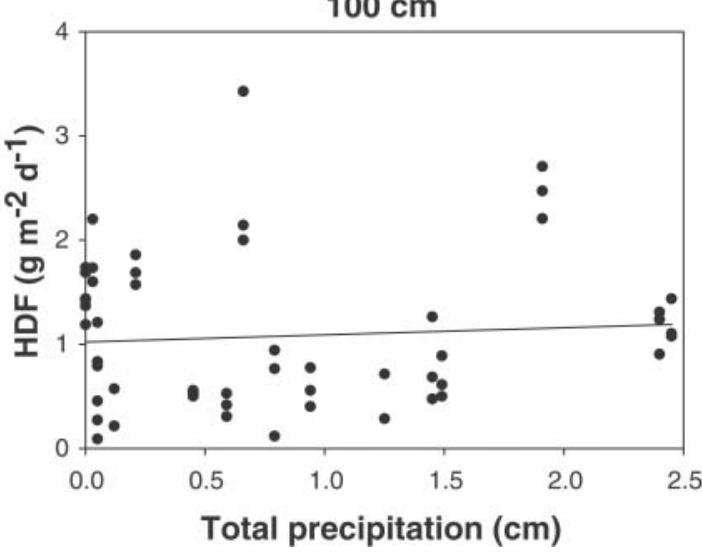

(b)
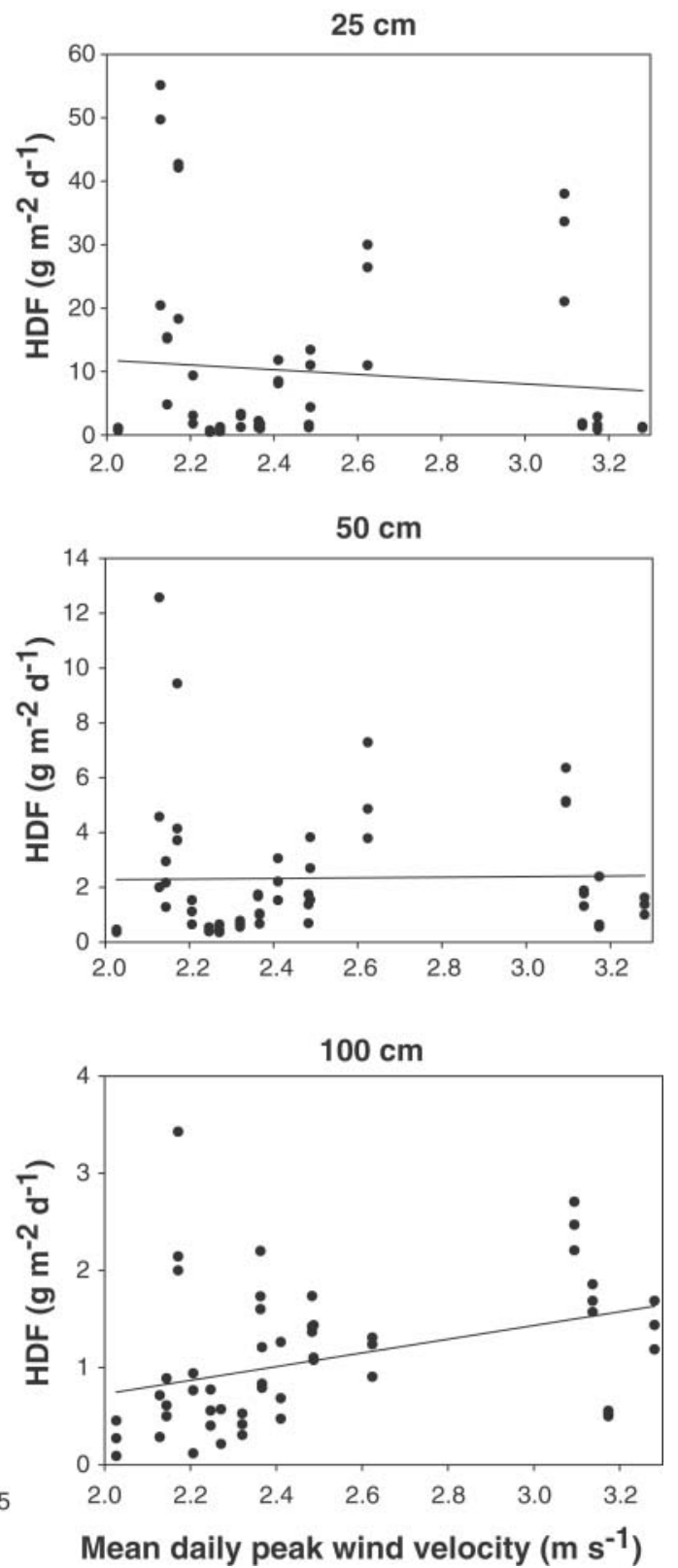

Fig. 4. The means of the horizontal dust flux as a function of precipitation (Column a) and wind velocity (Column b). The relationships are plotted individually for sampling heights of 25,50 , and $100 \mathrm{~cm}$.

rain-splash effects). Integrating these functions over the five sampling heights provided the total mass flux per unit width. A simple exponential model of the form $Y=$ $a \exp (b h)$ was used to describe this relationship, with $a$ and $b$ being estimated using an iterative least-squares method (StatSoft, 1994). The values for $a$ and $b$ and the associated standard errors were $2.64 \pm 1.19$ and $-0.87 \pm$ 0.29 , respectively, for the severely burned area, and 1.36 \pm 1.21 and $-0.65 \pm 0.32$, respectively, for the moderately burned location. The relationships were statistically significant $(P<0.05)$, but the coefficients of determination $\left(R^{2}\right)$ for these models were generally low and were 0.14 and 0.07 for the severely and moderately burned areas, respectively. Integrating these functions to a 1-m height gave an estimated total mass passing through a 1 -m-wide length of 1.76 and $1.00 \mathrm{~g} \mathrm{~m}^{-1} \mathrm{~d}^{-1}$ for the severely burned and moderately burned areas, respectively. The height profile of HDF in the unburned area did not vary significantly with sampling height, so a comparable estimate of HDF is simply the flux averaged across all three heights multiplied by the range of sampling heights $(1 \mathrm{~m})$. This gives an estimated mean of $0.74 \mathrm{~g} \mathrm{~m}^{-1} \mathrm{~d}^{-1}$ passing through the similar 1-m-wide length in the unburned areas. 




Fig. 5. Relationship between the VDF (vertical dust flux) measurements and the HDF (horizontal dust flux) measured at the TA-6 meteorological station. The regression equation is $\mathrm{VDF}=0.02+$ $0.05($ HDF $), R^{2}=0.37$.

\section{Relationship between Horizontal and Vertical Dust Flux}

A significant linear relationship was found between the HDF measurements (dependent variable) and the VDF measurements $\left(P<0.05, R^{2}=0.37\right)$. The intercept and slope with standard errors were $0.02 \pm 0.02$ and 0.05 \pm 0.02 , respectively. A plot of this relationship is shown in Fig. 5. This correlation suggests a link between HDF and VDF and the erosion and long-distance transport of soil and soil-bound contaminants that is implied by measures of VDF.

\section{Forest Recovery and Horizontal Dust Flux}

There was little indication of declining HDF with time since the fire. Measures of HDF were similar among years or showed trends of increasing HDF. The LCM comparing overlapping sampling intervals in severely burned areas indicated no increase in HDF from 2001 to 2002 at any elevation $(P>0.05)$ but significant increases in HDF between 2002 and 2003 at $0.25 \mathrm{~m}$ (LCM $F=$ 7.06 ; $\mathrm{df}=1,470 ; P<0.01)$ and $0.50 \mathrm{~m}(\mathrm{LCM} \mathrm{F}=18.1$; $\mathrm{df}=1,470 ; P<0.01)$. There was no significant increase from 2002 to 2003 at $1.0 \mathrm{~m}(P \geq 0.05)$. Linear contrasts of means using logarithmically transformed data from the moderately burned plots indicated no increase in HDF from 2001 to 2002 at any elevation $(P \geq 0.05)$ but significant increases in HDF between 2002 and 2003 at 0.50 and $1.0 \mathrm{~m}(\mathrm{LCM} F \mathrm{~s}>7$; df $=1,470 ; P<0.01)$.

\section{DISCUSSION}

There have been numerous studies on the effects of forest fires on water erosion and runoff, but this study is among the first to document wildfire effects on wind erosion in a forest ecosystem and one that is particularly vulnerable to wildfire (Covington, 2003; Friederici, 2003). Our results suggest that wildfire increases wind erosion. Specifically, HDF was significantly increased in burned areas, especially in the severely burned areas. The likely causes of increased HDF in the burned areas are decreased vegetation, litter, and tree cover that resulted in higher surface wind velocities (Whicker et al., 2002).

The use of BSNE samplers in this study differs somewhat from their use in previous studies. We were interested in obtaining and comparing measures of average dust flux occurring in differentially burned areas. The samplers allow collection during extended periods of time from representative areas. In some past studies, the samplers were used for short durations under wellmonitored specific conditions to obtain event-based measurements to quantify relationships between factors that affect the entrainment and suspension of particles. Our finding that the impact of the fire on HDF was most pronounced at the lower sampling heights was probably affected by rain splash at the 0.25 - and $0.5-\mathrm{m}$ sampling heights, and rain splash should be considered in future studies. Despite the potential effects of rain splash on HDF measurement, the statistical conclusion of increased HDF in burned areas held during dry periods, but the effect of forest burning was less. Increased rain splash in the burned areas may be explained by the facts that the burned areas had relatively more bare soil and the trees in the unburned areas moderate the effect by reducing raindrop sizes and velocities in the unburned areas. Regarding contaminated soils, increased rain splash and post-fire vegetation in burned areas suggests higher transfer rates of the contaminant to plant surfaces and subsequent ingestion by grazing animals (Dreicer et al., 1984). The lack of a pronounced decrease in HDF with sampling height during the dry periods was unexpected (Stout and Zobeck, 1996) and may be explained if a large fraction of the collected dust is not made up of saltating particles, but rather "background" atmospheric dust from distant sources filtered through the forest.

The possibility that much of the collected dust could be from distant sources is also supported by the percentage of total ground cover (Table 2), which is especially large relative to many wind erosion studies in agricultural settings. Results from Siddoway et al. (1965) and Gregory (1982) suggest that wind erosion is essentially controlled in agricultural fields with total ground cover $>50 \%$, as was measured in this study. There are few studies, however, in nonagricultural systems to predict how general relationships developed in agricultural systems translate into other environments. For example, the fact that total cover was $<50 \%$ may limit (not eliminate) wind erosion in more natural settings due to the patchy nature of vegetation and cover in these landscapes.

We were not able to begin measurements for this study until $\sim 1 \mathrm{yr}$ after the fire, and we may have missed important information on the full impact of the fire on dust flux. Specifically, one would expect that the effects of the fire on soil erosion would be greatest immediately following the fire because of significant loss of vegetation and litter cover and lack of recovery time. For the time period studied, however, we found that increased HDF in the burned areas persisted through July of 2003, $3 \mathrm{yr}$ post-fire, despite extensive remediation (Veenis, 2000). Comparisons of burn severities on tree and ground 
cover indicated that the effects of the Cerro Grande fire was similar to that for other fires in ponderosa pine forests, but the rates of recovery of ground vegetation and litter were slower than those for other fires (Pinder et al., 2004). The slower recoveries, which occurred even on those areas that were seeded and mulched, are probably due to the effects of ongoing drought.

\section{Ecological Implications}

Airborne dust is constantly being transported through environments (Pye, 1987), and this study showed that disturbances such as wildfire can significantly increase dust flux, and the increase can persist for years. This study reports estimates of 1-m integrated dust flux values of slightly more than $1 \mathrm{~kg}$ of dust passing through each meter in a burned forest per year, about 2.4 times that found in unburned forests and about five times that found for water erosion on shallow slopes (Johansen et al., 2001; Breshears et al., 2003). This could be a significant amount of increased dust mass when integrated over large tracts of forested land and over multiple years. The soil particle sizes and chemical constituents of the dust were not measured in this study, but the dust may be expected to be enriched in soil fines containing soil organic materials and associated soil nutrients, both important components for soil productivity. Future work should consider the chemical makeup of the dust to more fully understand the ecological impact of this enhanced redistribution of soil.

Soil is a key integrating factor in forest ecosystems because of the strong coupling between soil quality and the biotic components in the ecosystem that it supports. Loss of soil and associated nutrients is considered an important indicator of ecosystem function (Tongway and Ludwig, 1997; Whitford et al., 1998). The response of wind erosion to wildfire suggests that it could also respond to other disturbances; thus, wind erosion may be an important metric to be included in the assessment of impacts of ecosystem disturbance, forest management, and the trajectory of the recovery (Miller, 2004; Whicker et al., 2004b; Neff et al., 2005).

\section{Post-Fire Transport and Erosion by Water and Wind}

Wildfire increases both wind and water erosion, but there are few, if any, comparisons of the relative effects. Johansen et al. (2001) studied water erosion on mild slopes (4-8\%) using rainfall simulation on unburned plots and plots burned over by the Cerro Grande fire (in the same primary severely burned plot used in this study). Using the data from the Johansen et al. (2001) water erosion study and this wind erosion study, the effects of forest fire are compared qualitatively for severely burned areas.

The amount of increased wind erosion is estimated using the mean HDF values measured at $1 \mathrm{~m}$ during the study (averages of $0.73,1.18$, and $1.76 \mathrm{~g} \mathrm{~m}^{-2} \mathrm{~d}^{-1}$ at the unburned, moderate burn, and severe burn areas, respectively) and the empirically determined relationship between measured HDF and the VDF (Fig. 5). Estimated annual VDFs were $21 \mathrm{~g} \mathrm{~m}^{-2} \mathrm{yr}^{-1}$ [e.g., $365 \mathrm{~d}$ $\left.\mathrm{yr}^{-1}(0.020+0.73[0.053])\right]$ for unburned forests, $30 \mathrm{~g} \mathrm{~m}^{-2}$ $\mathrm{yr}^{-1}$ for moderately burned forests, and $41 \mathrm{~g} \mathrm{~m}^{-2} \mathrm{yr}^{-1}$ for severely burned forests. These estimates of upward net VDFs are most applicable to the moderately and severely burned locations because of similar ground and tree cover to the TA-6 location where they were made. The vertical flux estimates suggest an approximate $95 \%$ relative increase in vertical flux and an absolute increase of $20 \mathrm{~g} \mathrm{~m}^{-2} \mathrm{yr}^{-1}$ in the severely burned area. Though a significant increase, the measured erosion rate in the burned forest is still quite low relative to agricultural fields, which can also be considered a disturbed environment (Lal et al., 2003).

The $95 \%$ increase in wind erosion appears small when compared with the $>20 \times$ post-fire increase in sediment yield (approximate means of $3-70 \mathrm{~kg} \mathrm{ha}^{-1} \mathrm{~mm}^{-1}$ ) through water erosion observed at LANL by Johansen et al. (2001). Breshears et al. (2003) used (i) the frequency and magnitude of precipitation events for the LANL site and (ii) the rainfall simulation plot data of Johansen et al. (2001) on an unburned forest plot to estimate water-driven erosion rates of approximately $1 \mathrm{~g}$ $\mathrm{m}^{-2} \mathrm{yr}^{-1}$ before the fire. Assuming a 20 -fold increase in water erosion in severely burned areas gives an estimated water erosion rate of $20 \mathrm{~g} \mathrm{~m}^{-2} \mathrm{yr}^{-1}$ after the fire. This would suggest an increase of $19 \mathrm{~g} \mathrm{~m}^{-2} \mathrm{yr}^{-1}$ due to water erosion following a fire; however, this water erosion study was conducted within a few months of the Cerro Grande fire and a significant fraction of the collected mass was ash. Our wind erosion measurements started the following year, when much of the ash had eroded away and some vegetation recovery had occurred. Thus, this comparison is likely to be biased toward greater water erosion.

The previous assessment of the impacts of fire on wind erosion rates is based on two assumptions concerning the HDF measures in the unburned forest. The first is that the relationship between HDF and VDF observed for the TA-6 location is also valid for the forest. It is reasonable to challenge this assumption. The levels of canopy coverage and the tree heights (Table 1) would suggest less vertical air movement and mixing. Thus, the ratio of VDF to HDF may be less for unburned forests. The application of the relationship shown in Fig. 5 to severe burn areas is more plausible because of the loss of the effects of canopy coverage and foliage mass on wind mixing following the fire. The second assumption is that all the material measured as HDF in the forest is local erosion. This assumption may not be valid. The collected material may be partly or mostly deposition of airborne particulates from distant sources filtering through the canopy. Failure of either of these assumptions results in overestimation of vertical flux for the forest and a corresponding underestimation of the increased rate of wind erosion. Thus, the comparison of the increases in water and wind erosion rates following fire as presented above may be biased and underestimate the relative importance of wind erosion. This underestimation may be as much as $200 \%$ [100\% $(41-0) /(41-21)]$. 


\section{Implications for Transport of Soil-Bound Contaminants}

Rates of wind-driven transport and erosion underlie any assessment for human or ecological risk where the wind-driven pathway is of concern. Our results provide data on such rates in a major ecosystem type for the western USA - ponderosa pine forest-and provide some of the first estimates of how much those rates increase in response to a major type of ecosystem disturbance-wildfire. The specific risks will be dependent on other additional factors such as size distribution of dust particles, the associated size distribution for contaminant particles, and the contaminant chemical properties (Whicker and Schultz, 1982), the later two of which will vary with contaminant type. Nonetheless, our findings provide underlying rates relevant for assessing risk for a diverse suite of contaminants. Post-fire water erosion at our site was related to ${ }^{137} \mathrm{Cs}$ transport (Johansen et al., 2003); we expect that post-fire wind erosion will be similarly related to transport of ${ }^{137} \mathrm{Cs}$ and other soil-bound contaminants, although this will require future study.

Regarding contaminant transport, wildfires probably increase local redistribution of contaminated soils through wind, and the effects can last for years depending on the recovery of the vegetation and litter cover. This local redistribution may concentrate contaminants in vegetation and in areas of aeolian deposition such as in areas of higher canopy cover or leeward sides of topographic objects such as hills and canyons where the wind velocity is lower (Whicker and Schultz, 1982; Ritchie and McHenry, 1990; Coppinger et al., 1991; Sutherland et al., 1991; Gonzales et al., 2001; Toy et al., 2002). Importantly, forest fires may also increase long-range (several kilometers) transport of contaminants and increase exposures to the public, as shown in the relationship between the VDF and the HDF found in this study. As an example, LANL (2002) shows that depleted U air concentrations at the LANL boundaries have significantly increased following the Cerro Grande fire, though the levels remain low and within regulated safety standards. This study, however, confirms the value of data-based risk assessments following environmental disturbance.

\section{CONCLUSIONS}

Wildfire has been shown to increase HDF, especially in severely burned locations and, to a lesser degree, in moderately burned locations. The increased dust fluxes continued for several years following the fire, probably because of continuing drought, which has slowed the recovery of ground vegetation. The finding of increased HDF and VDF implies that wind-driven mobility of soilbound contaminants may have also increased. This potential increase in contaminant mobility at LANL following the Cerro Grande fire is supported by increased air concentrations of depleted $\mathrm{U}$, which has been distributed in the local environment through explosive testing (Los Alamos National Lab., 2002). On a broader scale, the results of this study have important implica- tions for soil quality, biogeochemistry, ecosystem health, and risks associated with contaminant transport.

\section{ACKNOWLEDGMENTS}

This work was funded, in part, by the Technology, Development, Enhancement, and Application program at Los Alamos National Laboratory and the remainder was funded by the Department of Energy under contract W7405 ENG-36. The support of Shawna Eisele, Jeffrey Hoffman, Dr. Robert Devine, and Dr. Robert Murphy is greatly appreciated. We would like to thank Kristine N. Baker for data collection and the following individuals for their valuable contributions to this study: Dr. Shawki Ibrahim, Dr. Jeff Collett, Dr. John Zimbrick, and Dr. Ted Zobeck.

\section{REFERENCES}

Aguiar, M.R., and O.E. Sala. 1999. Patch structure, dynamics and implications for the functioning of arid ecosystems. Tree 14:273-277.

Anspaugh, L.R., J.H. Shinn, P.L. Phelps, and N.C. Kennedy. 1975. Resuspension and redistribution of plutonium in soils. Health Phys. 29:571-582

Baker, M.B., Jr., and R.L. Jemison. 1991. Soil loss-key to understanding site productivity. p. 71-76. In Proc. Annu. Meet. Agencies and Science Working Together for the Future, 36th, Las Cruces, NM. 7-9 Nov. 1991. Rep. 265. New Mexico Water Research Inst., New Mexico State Univ., Las Cruces.

Baldocchi, D. 1997. Flux footprints within and over forest canopies. Boundary Layer Meteorol. 85:273-292.

Blackadar, A.K. 1997. Turbulence and diffusion in the atmosphere. Springer, New York.

Breshears, D.D., J.J. Whicker, M.P. Johansen, and J.E. Pinder III. 2003. Wind and water erosion and transport in semiarid shrubland, grassland, and forest ecosystems: Quantifying dominance of horizontal wind-driven transport. Earth Surf. Processes Landforms 28:1189-1209.

Coppinger, K.D., W.A. Reiners, and R.K. Olson. 1991. Net erosion on a sagebrush steppe landscape as determined by cesium-137 distribution. Soil Sci. Soc. Am. J. 55:254-258.

Covington, W.W. 2003. The evolutionary and historical context. p. 26-47. In P. Friederici (ed.) Ecological restoration of southwestern ponderosa pine forests. Island Press, Washington, DC.

Dreicer, M., T.E. Hakonson, G.C. White, and F.W. Whicker. 1984. Rainsplash as a mechanism for soil contamination of plant surfaces. Health Phys. 46:177-188.

Finkle, H.J. 1986. Semiarid soil and water conservation. CRC Press, Boca Raton, FL.

Freedman, B. 1995. Environmental ecology: The ecological effects of pollution, disturbance, and other stresses. Academic Press, San Diego, CA.

Fresquez, P.R., D.R. Armstrong, and M.A. Mullen. 1998. Radionuclides in soils collected from within and around Los Alamos National Laboratory. J. Environ. Sci. Health A 33:263-278.

Friederici, P. (ed.). 2003. Ecological restoration of southwestern ponderosa pine forests. Island Press, Washington, DC.

Fryrear, D.W. 1985. Soil cover and wind erosion. Trans. ASAE 28: 781-784.

Fryrear, D.W. 1986. A field dust sampler. J. Soil Water Conserv. 41: $117-120$.

Gillette, D.A., D.W. Fryrear, J.B. Xiao, P. Stockton, D. Ono, P.J. Helm, T.E. Gill, and T. Lee. 1997. Large-scale variability of wind erosion mass flux rates at Owens Lake: I. Vertical profiles of horizontal mass fluxes of wind-eroded particles with diameter greater than 50 $\mu \mathrm{m}$. J. Geophys. Res. 102:25977-25987.

Gonzales, G.J., P.R. Fresquez, and C.M. Bare. 2001. Contaminant concentrations in conifer tree bark and wood following the Cerro Grande fire. Los Alamos Natl. Lab. Rep. LA-UR-01-6157. Los Alamos Natl. Lab., Los Alamos, NM.

Goossens, D., and Z.Y. Offer. 2000. Wind tunnel and field calibration of six aeolian dust samplers. Atmos. Environ. 34:1043-1057.

Goossens, D., and M. Riksen (ed.). 2004. Wind erosion and dust 
dynamics: Observations, simulations, modeling. ESW Publ., Wageningen, the Netherlands.

Gregory, J.M. 1982. Soil cover predictions with various amounts and types of crop residue. Trans. ASAE 25:1333-1337.

Griffin, D.W., C.A. Kellogg, and E.A. Shinn. 2001. Dust in the wind: Long range transport of dust in the atmosphere and its implications for global public and ecosystem health. Global Change Human Health 2:20-33.

Hinds, W.C. 1982. Aerosol technology: Properties, behavior, and measurement of airborne particles. John Wiley \& Sons, New York.

Johansen, M.P., T.E. Hakonson, and D.D. Breshears. 2001. Post-fire runoff and erosion from rainfall simulation: Contrasting forests with shrublands and grasslands. Hydrol. Processes 15:2953-2965.

Johansen, M.P., T.E. Hakonson, F.W. Whicker, and D.D. Breshears. 2003. Pulsed redistribution of a contaminant following forest fire: Cs-137 in runoff. J. Environ. Qual. 32:2150-2157.

Kaiser, J. 2004. Wounding earth's fragile skin. Science (Washington, DC) 304:1616-1618.

Kraig, D., R. Ryti, D. Katzman, T. Buhl, B. Gallaher, and P. Fresquez. 2001. Radiological and nonradiological effects after the Cerro Grande fire. Los Alamos Natl. Lab. Rep. LA-UR-01-6868. Los Alamos Natl. Lab., Los Alamos, NM.

Lal, R., T.M. Sobecki, T. Iivari, and J.M. Kimble. 2003. Soil degradation in the United States: Extent, severity, and trends. Lewis Publ., Boca Raton, FL.

Larney, F.J., A.J. Cessna, and M.S. Bullock. 1999. Herbicide transport on wind-eroded sediment. J. Environ. Qual. 28:1412-1421.

Lemmon, P.E. 1956. A spherical densitometer for estimating overstory density. For. Sci. 2:314-320.

Littell, R.C., G.A. Milliken, W.W. Stroup, and R.D. Wolfinger. 1996. SAS system for mixed models. SAS Inst., Cary, NC.

Los Alamos National Laboratory. 2000. A special edition of the SWEIS yearbook: Wildfire 2000. Rep. LA-UR-00-3471. Los Alamos Natl. Lab., Los Alamos, NM.

Los Alamos National Laboratory. 2002. Environmental surveillance at Los Alamos during 2002. Rep. LA-14086-ENV. Los Alamos Natl. Lab., Los Alamos, NM.

Ludwig, J.A., R.W. Eager, G.N. Bastin, V.H. Chewings, and A.C. Liedloff. 2002. A leakiness index for assessing landscape function using remote sensing. Landsc. Ecol. 17:157-171.

McCabe, G.J., M.A. Palecki, and J.L. Betancourt. 2004. Pacific and Atlantic Ocean influences on multidecadal drought frequency in the United States. Proc. Natl. Acad. Sci. USA 101:4136-4141.

McNeill, J.R., and V. Winiwarter. 2004. Breaking the sod: Humankind, history, and soil. Science (Washington, DC) 304:1627-1629.

Miller, M.E. 2004. The structure and functioning of dryland ecosystems: Conceptual models to inform the vital-sign selection process. USGS February Draft Rep. U.S. Geol. Surv., Moab, UT.

Milliken, G.A., and D.E. Johnson. 1984. The analysis of messy data. Vol. 1. Designed experiments. Van Nostrand Reinhold Co., New York.

National Academy of Science. 1989. Nuclear weapons complex: Management for health, safety and the environment. National Academy Press, Washington, DC.

Neff, J.C., R.L. Reynolds, J. Belnap, and P. Lamothe. 2005. Multidecadal impacts of grazing on soil physical and biogeochemical properties in Southeast Utah. Ecol. Appl. 15:87-95.

Nyhan, J.W., L.W. Hacker, T.E. Calhoun, and D.L. Young. 1978. Soil survey of Los Alamos County, New Mexico. Los Alamos Scientific Lab. Rep. LA-6779-MS. Los Alamos Natl. Lab., Los Alamos, NM.

Nyhan, J.W., S.W. Koch, R.G. Balice, and S.R. Loftin. 2001. Estimation of soil erosion in burnt forest areas of the Cerro Grande fire in Los Alamos, New Mexico. Los Alamos Natl. Lab. Rep. LA-UR-014658. Los Alamos Natl. Lab., Los Alamos, NM.

Okin, G.S., B. Murray, and W.H. Schlesinger. 2001. Degradation of sandy arid shrubland environments: Observations, process modeling, and management implications. J. Arid Environ. 47:123-144.

Pimentel, D. 2000. Soil as an endangered ecosystem. Bioscience 50:947.

Pinder, J.E., J.J. Whicker, and D.D. Breshears. 2004. Effects of the Cerro Grande fire on ponderosa pine forests and recovery of the forest floor at LANL. Los Alamos Natl. Lab. Rep. LA-UR-04-2495. Los Alamos Natl. Lab., Los Alamos, NM.

Pye, K. 1987. Aeolian dust and dust deposits. Academic Press, Orlando, FL.
Rishel, J., S. Johnson, and D. Holt. 2003. Meteorological monitoring at Los Alamos. Los Alamos Natl. Lab. Rep. LA-UR-03-8097. Los Alamos Natl. Lab., Los Alamos, NM.

Ritchie, J.C., and J.R. McHenry. 1990. Application of radioactive fallout cesium-137 for measuring soil erosion and sediment accumulation rates and patterns: A review. J. Environ. Qual. 19:215-233.

Rodgers, P. 1996. Disturbance ecology and forest management: A review of the literature. Gen. Tech. Rep. INT-GTR-336. USDA Forest Serv., Intermountain Res. Stn., Ogden, UT.

Saxton, K.E. 1995. Wind erosion impacts on off-site air quality in the Columbia Plateau: An integrated research plan. Trans. ASAE 38: 1031-1038.

Schlesinger, W.H., and A.M. Pilmanis. 1998. Plant-soil interactions in deserts. Biogeochemistry 42:169-187.

Selmants, P.C., A. Elseroad, and S.C. Hart. 2003. Soil and nutrients. p. 144-160. In P. Friederici (ed.) Ecological restoration of southwestern ponderosa pine forests. Island Press, Washington, DC.

Siddoway, F.H., W.S. Chepil, and D.V. Armbrust. 1965. Effect of kind, amount, and placement of residue on wind erosion control. Trans. ASAE 8:327-331.

StatSoft. 1994. Statistica for Windows. Vol. 1. General conventions and statistics I. StatSoft release 5.0. StatSoft, Tulsa, OK.

Stout, J.E. 1990. Wind erosion in a simple field. Trans. ASAE 33: $1597-1600$.

Stout, J.E., and T.M. Zobeck. 1996. The Wolfforth field experiment: A wind erosion study. Soil Sci. 161:616-632.

Sutherland, R.A., T. Kowalchuk, and E. De Jong. 1991. Cesium-137 estimates of sediment redistribution by wind. Soil Sci. 151:387-396.

Swetnam, T.W., and J.L. Betancourt. 1998. Mesoscale disturbance and ecological response to decadal climatic variability in the American Southwest. J. Clim. 11:3128-3147.

Tegen, I., A.A. Lacis, and I. Fung. 1996. The influence of climate forcing of mineral aerosols from disturbed soils. Nature (London) 380: 419-422.

Tongway, D.J., and J.A. Ludwig. 1997. The conservation of water and nutrients within landscapes. p. 13-22. In J. Ludwig et al. (ed.) Landscape function and management: Principles from Australia's rangelands. CSIRO Publ., Melbourne, Australia.

Toy, T.J., G.R. Foster, and K.G. Renard. 2002. Soil erosion: Processes, prediction, measurement and control. John Wiley \& Sons, New York.

Veenis, S. 2000. After the fire. Erosion Control, November-December. Available at http://forester.net/ec_0011_fire.html (accessed on 25 Sept. 2005; verified 1 Nov. 2005). Forester Communications, Santa Barbara, CA.

Wardle, D.A., R.D. Bardgett, J.N. Klironomos, H. Setälä, W.H. van der Putten, and D.H. Wall. 2004. Ecological linkages between aboveground and belowground biota. Science (Washington, DC) 304: 1629-1633.

Whicker, F.W., T.G. Hinton, M.M. MacDonell, J.E. Pinder III, and L.J. Habegger. 2004a. Avoiding destructive remediation at DOE sites. Science (Washington, DC) 303:1615-1616.

Whicker, F.W., and V. Schultz. 1982. Radioecology: Nuclear energy and the environment. CRC Press, Boca Raton, FL.

Whicker, J.J., D.D. Breshears, P.T. Wasiolek, T.B. Kirchner, R.A. Tavani, D.A. Schoep, and J.C. Rodgers. 2002. Temporal and spatial variation of episodic wind erosion in unburned and burned semiarid shrubland. J. Environ. Qual. 31:599-612.

Whicker, J.J., J.E. Pinder III, D.D. Breshears, and K.N. Baker. 2004b. Secondary effects of thinning in ponderosa pine forests: Wind erosion as an ecosystem health metric. Proc. Symp. Biological Res. in the Jemez Mountains, New Mexico, 8th, Santa Fe, NM. 24 Feb. 2004. National Park Serv., Bandelier Natl. Monument, Los Alamos, NM.

Whitford, W.G. 2002. Ecology of desert systems. Academic Press, London, UK.

Whitford, W.G., A.G. DeSoyza, J.W. Van Zee, J.E. Herrick, and K.M. Havstad. 1998. Vegetation, soil, and animal indicators of rangeland health. Environ. Monit. Assess. 51:179-200.

Zobeck, T.M., D.W. Fryrear, and R.D. Pettit. 1989. Management effects on wind-eroded sediment and plant nutrients. J. Soil Water Conserv. 44:160-163.

Zobeck, T.M., G. Sterk, R. Funk, J.L. Rajot, J.E. Stout, and R.S. Van Pelt. 2003. Measurement and data analysis for field-scale wind erosion studies and model validation. Earth Surf. Processes Landforms 28:1163-1188. 